\title{
Stock Selection Based on Fundamental Analysis Approach by Grey Relational Analysis: A Case of Turkey
}

\author{
Mehmet Fatih Bayramoglu ${ }^{1,2} \&$ Coskun Hamzacebi ${ }^{3}$ \\ ${ }^{1}$ Department of Business Administration, Bulent Ecevit University, Zonguldak, Turkey \\ ${ }^{2}$ Visiting Professor, Department of Economics and Finance, Lamar University, TX, USA \\ ${ }^{3}$ Department of Industrial Engineering, Karadeniz Technical University, Trabzon, Turkey \\ Correspondence: Mehmet Fatih Bayramoglu, Department of Business Administration, Bulent Ecevit University, \\ Zonguldak 67100, Turkey. Visiting Professor, Department of Economics and Finance, Lamar University, TX \\ 77710, USA. Tel: 1-409-554-1121. E-mail: fatih.bayramoglu@beun.edu.tr
}

Received: April 11, 2016

doi:10.5539/ijef.v8n7p178
Accepted: May 11, 2016

Online Published: June 25, 2016

URL: http://dx.doi.org/10.5539/ijef.v8n7p178

\begin{abstract}
Determining financial assets for investment is a significant problem for investors. Especially, since it is riskier in comparison with other financial assets, selecting common stock is not only important for investors but also, it is a complicated decision-making process, because, although they agree to accept a risk, common stock investors tend to keep the risk they undertake at a given level. With this purpose, investors prefer to conduct various analysis and predictions to decide which common stocks they will invest. In this study, by using micro and macro variables, which have been determined with a fundamental analysis approach, a common stock selection is conducted for nine different corporations doing activities in ten lines of business in Borsa Istanbul. In the study, Grey Relational Analysis (GRA), which is developed in the framework of Grey System Theory, is used as a mathematical model. Therefore, a conclusion is obtained about which parameters are more important in selecting a common stock, and the efficiency of GRA Method is tested.
\end{abstract}

Keywords: stock selection, fundamental analysis, grey relational analysis, beta coefficient, Borsa Istanbul

\section{Introduction}

There are much multiple-criteria decision making (MCDM) in our daily life (Kou et al., 2008, Huang et al., 2004). Different from single-criteria decision-making problem, MCDM aims to select the best from the existing "alternatives", "policies", "actions", or "candidates", by considering multiple "attributes," goals," or "criteria," which are frequently in conflict with each other. Therefore, how to make a trade-off between these conflicting attributes and then make a decision could pose a severe problem (Kuo et al., 2008).

In their daily decisions, people implicitly consider the risks they face. In an increasingly complex world, the resulting decisions are not always appropriate because the limits of the human mind do not allow for an implicit consideration of a vast number of different factors. In the past, many lessons had to be learned by trial and error. In a similar manner, a formal analysis may contribute to the decision-making process in complex situations (Bohnenblust \& Slovic, 1998).

Many decisions are made under uncertain and/or incomplete information. The analysis of such decision-making is an interesting topic, and many researchers have been engaged with these decision-making problems (Huang et al., 2004).

There are several common methodologies for MCDM are developed such as Analytic Hierarchy Process (AHP), Analytic Network Process (ANP), Data Envelopment Analysis (DEA), Elimination et Choix Traduisant la Realite (ELECTRE), Preference Ranking Organization Method for Enrichment Evaluation (PROMETHEE), Simple Additive Weighting (SAW) Technique for Order Preference by Similarity to Ideal Solution (TOPSIS), Grey Relational Analysis (GRA), etc.

Stock investment is accepted as a decision-making problem in the science of finance. The critical issue for decision-making in stock trading is a selection of the right stock at the right time. There are many analytical approaches for decision making in a stock exchange, which are categorized in two groups of technical analysis 
and fundamental analysis (Albadvi et al., 2007).

Technical analysis involves the use of historical market data, such as price, volume, and other observables, to predict future returns on financial assets (Yamamoto, 2012). Fundamental analysis involves audit reports, financial statements, management capabilities and stock's rate of return, beta coefficient and other return and risk parameters (Albadvi et al., 2007, Dhatt et al., 1999, Mukherji et al., 1997, Markowitz, 1952).

In this study, the purpose is to determine macroeconomic and individual micro variables, which can contribute to the decision-making process in a stock selection application within the framework of Grey Relational Analysis Method and basic analysis approach. The reason why such a base has been chosen for the study is that the stock selection process in a portfolio investment plays an important role as much as a determination of stock investment rates to be made since the step of determination of capital allocation rates is the succeeding step after the stock selection process. However, neither Traditional Portfolio Approaches nor Modern Portfolio Theory presents a proactive proposition for the issue of stock selection. Markowitz OV Model, as one of the leading modern approaches, makes a stock selection in the optimization phase. For the previous phases, the only proposition of the Model is selecting stocks from different lines of business. However, it is also possible to select best stocks among the set of assets thanks to a stock analysis to be conducted with mathematical models before the optimization phase. In this way, a more efficient optimization process can be performed. As such, the primary purpose of this study measures the efficiencies of Beta coefficient, the rate of return, standard deviation, and coefficient of variation as the variables of fundamental analysis, which are used in stock selection, through GRA method.

\section{Grey Relational Analysis (GRA)}

In grey system theory, according to the degree of information, if the system information is fully known, the system is called a white system; if the information is unknown, it is referred to as a black system. A system with information known partially is known as a grey system. The grey system theory includes five major parts: (i) grey prediction, (ii) grey relational analysis (GRA), (iii) grey decision, (iv) grey programming and (v) grey control. GRA is part of Grey System Theory, which is suitable for solving problems with complicated interrelationships between multiple factors and variables (Wei, 2011).

GRA is a tool of grey system theory for analyzing the relationship between a reference series and other series. Grey system theory was developed by Julong Deng in 1982. The GRA is a quantitative analysis to explore the similarity and dissimilarity among factors in developing a dynamic process (Deng, 1989). More clearly, GRA is a method used to determine the relational degree between each factor in a grey system and compared factor series. Every factor is defined as a sequence. The degree of inter-factorial influence is called as a grey relational degree. In other words, GRA aims to measure the similarity between the compared series. The GRA methodology is as follows (Hamzaçebi \& Pekkaya, 2011):

Step 1. Define the problem: alternatives $(i=1, \ldots, m)$, criteria $(j=1, \ldots, n)$,

$$
\chi_{i}=\left(\chi_{i}(1), \chi_{i}(2), \chi_{i}(3), \ldots, \chi_{i}(n)\right)
$$

Step 2. Determine the reference series: reference series may come into existence via the minimum or the maximum - if the criteria require the maximization (minimization) the reference sequence value of the related criteria is the maximum (minimum) value of the alternative series - values of the alternative set or nominal value.

$$
\chi_{0}=\left(\chi_{0}(1), \chi_{0}(2), \chi_{0}(3), \ldots, \chi_{0}(n)\right)
$$

Step 3. Normalization: in order the make the values free of a unit the normalization process is done. This process is called grey relational generating. The normalization process can occur in three types:

i. Higher is better:

$$
\chi_{i}(k)=\frac{\chi_{i}^{0}(k)-\min \chi_{i}^{0}(k)}{\max \chi_{i}^{0}(k)-\min \chi_{i}^{0}(k)}
$$

ii. Lower is better:

$$
\chi_{i}(k)=\frac{\max \chi_{i}^{0}(k)-\chi_{i}^{0}(k)}{\max \chi_{i}^{0}(k)-\min \chi_{i}^{0}(k)}
$$

iii. Nominal is better: 


$$
\chi_{i}(k)=\frac{\left|\chi_{i}^{0}(k)-\chi^{0}\right|}{\max \chi_{i}^{0}(k)-\chi^{0}}
$$

where $\chi_{i}(k)$ is the value after the normalization, $\chi_{i}^{0}(k)$ is the value before the normalization, and $\min \chi_{i}^{0}(k)$, $\max \chi_{i}^{0}(k)$ are the smallest and largest values of the $k^{\text {th }}$ response before the normalization respectively.

Step 4. Calculate the grey relational coefficient: Grey Relational Coefficient (GRC) is an indicator of the similarity between the reference series and alternative series.

$$
\varepsilon\left(\chi_{0}(k), \chi_{i}(k)\right)=\frac{\Delta_{\min }+\xi \Delta_{\max }}{\Delta_{0 i}(k)+\xi \Delta_{\max }}
$$

Step 5. Calculate the Grey Relational Grade (GRG): GRG is used for overall evaluation of alternatives depending on all criteria. If all criteria have equal importance, the GRG can be calculated by Eq. (9), for different importance degree of the criteria, the GRG can be calculated by Eq. (10). The GRG values are used to rank the alternatives according to the similarity to reference series. The higher GRG value indicates the higher similarity.

$$
\begin{aligned}
& \gamma\left(\chi_{0}, \chi_{i}\right)=\frac{1}{n} \sum_{k=1}^{n} \varepsilon\left(\chi_{0}(k), \chi_{i}(k)\right) \\
& \gamma\left(\chi_{0}, \chi_{i}\right)=\sum_{k=1}^{n} w_{i}(k) \varepsilon\left(\chi_{0}(k), \chi_{i}(k)\right)
\end{aligned}
$$

It is evident to see that the GRA method is being used in various decision-making processes under the framework of the science of finance when one analyzes the current related literature. The Grey Relational Analysis Method was employed by Fang-Min and by Wang-Ching (2010) and by Ho (2006) in ratio analysis, by Liu et al. (2015) in analysis of house-purchase behaviors, by Huang and Jane (2009) in the determination of investment rates of stocks, by Chen et al. (2014) in forecasting of REIT returns, by Hamzaçebi and Pekkaya (2011) in decision making on stock selection, by Lin and Wu (2011) and by Doğan (2013) in measuring the performances of banks, by Kung and Wen (2007) and by Lee et al. (2012) in measuring company performances, by Wang et al. (2015) in capturing of customer requirements, by Guo et al. (2015) in forecasting of new product diffusion, by Birgun and Gungör (2014) in selection of call center sites, by Pan and Leu (2016) in analysis of bank service satisfaction, by Camelia et al. (2013) in analysis of financial sector in Europe, by Wang et al. (2014) in measuring tourism companies in Taiwan, by Kaygisiz et al. (2015) in evaluation of banks' commercial credit applications, by Sabau-Popa and Bolos (2014) in investigating the effects of macroeconomic variables on Bucharest Stock Exchange, and by Wang et al. (2014) in investment decision making process.

\section{Data}

In this study, a stock selection process in the Borsa Istanbul is conducted as a decision-making process. The study includes nine different companies conducting activities in ten lines of business. These companies are ALCTL, ANELT, ARENA, ESCOM, INDES, NETAS (Technology - Information Technology), RYSAS (Transportation, Communication and Storage - Transportation - Other Services Related Transport), INTEM (Wholesale and Retail Trade - Wholesale and Retail Trade, Hotels and Restaurants - Lumber and Building Material Wholesale Trade) and SELEC (Textile, Apparel, Furniture Wholesale Trade - Wholesale and Retail Trade, Hotels and Restaurants - Wholesale Trade).

In the developed model, four different independent variables as Beta coefficient (BC), the rate of return (RoR), standard deviation (STD) and coefficient of variation (CV) are used. Independent variables are calculated separately for each of the stocks. The dependent variables are the rates of returns of stocks in the following month.

Why the dependent and independent variables have been determined by the risk - return perspective is the theory itself is based on risk and income (Markowitz, 1952). As such, it is assumed that these parameters are important decision factors in stock selection. Besides, since business line diversification is another constituent of the Modern Portfolio Theory, the assets, which are used in this empirical study, are selected from different industries.

The study covers a period of 13 months from December 2011 to December 2012 as the term of monthly analysis. 
In the modeling phase, the time series are established with an assumption that the values of independent variables at the date of $t-1$ will affect the value of the dependent variable at the date of $t$. Consequently, the values of the period between December 2011 and November 2012 are used for independent variables. Providing a more reliable calculation of these variables, the time of the data is expanded between January 2007 and November 2012. When the values of the period between January 2012 and December 2012 are used as the dependent variable. The data are obtained from DirectFN ${ }^{\mathrm{TM}}$.

Table 1. Results of simulations

\begin{tabular}{|c|c|c|c|c|c|c|c|c|c|}
\hline \multicolumn{5}{|c|}{ SIMULATION - 1} & \multicolumn{5}{|c|}{ SIMULATION - 2} \\
\hline Months & \multicolumn{2}{|c|}{ SCC for Modeling } & \multicolumn{2}{|c|}{ SCC for Test } & Months & \multicolumn{2}{|c|}{ SCC for Modeling } & \multicolumn{2}{|c|}{ SCC for Test } \\
\hline 1 & \multicolumn{2}{|c|}{0.0667} & \multicolumn{2}{|c|}{0.2500} & 1 & \multicolumn{2}{|c|}{-0.3000} & \multicolumn{2}{|c|}{0.2833} \\
\hline 2 & \multicolumn{2}{|c|}{0.3833} & \multicolumn{2}{|c|}{0.1500} & 2 & \multicolumn{2}{|c|}{0.3167} & \multicolumn{2}{|c|}{0.0500} \\
\hline 3 & \multicolumn{2}{|c|}{0.2750} & \multicolumn{2}{|c|}{-0.2167} & 3 & \multicolumn{2}{|c|}{0.1083} & \multicolumn{2}{|c|}{-0.3833} \\
\hline 4 & \multicolumn{2}{|c|}{0.3000} & \multicolumn{2}{|c|}{0.1500} & 4 & \multicolumn{2}{|c|}{0.3500} & \multicolumn{2}{|c|}{0.0667} \\
\hline 5 & \multicolumn{2}{|c|}{0.0333} & \multicolumn{2}{|c|}{0.6333} & 5 & & & & \\
\hline 6 & & & & & 6 & & & & \\
\hline Parameters & $\mathrm{BC}$ & RoR & STD & $\mathrm{CoV}$ & Parameters & $\mathrm{BC}$ & RoR & STD & $\mathrm{CoV}$ \\
\hline Weights & 1 & 0 & 0 & 0 & Weights & 0.6 & 0 & 0.35 & 0.05 \\
\hline & & ATION & & & & & ATION & & \\
\hline Months & $\mathrm{SCC} f$ & deling & $\mathrm{SCC}$ & Test & Months & SCC & deling & & Test \\
\hline 1 & & & & & 1 & & & & \\
\hline 2 & & & & & 2 & & & & \\
\hline 3 & & & & & 3 & & & & \\
\hline 4 & & & & & 4 & & & & \\
\hline 5 & & & & & 5 & & & & \\
\hline 6 & & & & & 6 & & & & \\
\hline Parameters & $\mathrm{BC}$ & RoR & STD & $\mathrm{CoV}$ & Parameters & $\mathrm{BC}$ & RoR & STD & $\mathrm{CoV}$ \\
\hline Weights & 0.8 & 0.1 & 0.1 & 0 & Weights & 0.75 & 0.05 & 0.15 & 0.05 \\
\hline & & ATION & & & & & ATION & & \\
\hline Months & $\mathrm{SCC} f$ & deling & $\mathrm{SCC}$ & Test & Months & SCC & deling & & Test \\
\hline 1 & & & & & 1 & & & & \\
\hline 2 & & & & & 2 & & & & \\
\hline 3 & & & & & 3 & & & & \\
\hline 4 & & & & & 4 & & & & \\
\hline 5 & & & & & 5 & & & & \\
\hline 6 & & & & & 6 & & & & \\
\hline Parameters & $\mathrm{BC}$ & RoR & STD & $\mathrm{CoV}$ & Parameters & $\mathrm{BC}$ & RoR & STD & $\mathrm{CoV}$ \\
\hline Weights & 0.95 & 0.05 & 0 & 0 & Weights & 0.85 & 0.05 & 0.05 & 0.05 \\
\hline & & ATION & & & & & ATION & & \\
\hline Months & $\mathrm{SCC} f$ & deling & $\mathrm{SCC}$ & Test & Months & SCC & deling & & Test \\
\hline 1 & & & & & 1 & & & & \\
\hline 2 & & & & & 2 & & & & \\
\hline 3 & & & & & 3 & & & & \\
\hline 4 & & & & & 4 & & & & \\
\hline 5 & & & & & 5 & & & & \\
\hline 6 & & & & & 6 & & & & \\
\hline Parameters & $\mathrm{BC}$ & RoR & STD & $\mathrm{CoV}$ & Parameters & $\mathrm{BC}$ & RoR & STD & $\mathrm{CoV}$ \\
\hline Weights & 0.8 & 0 & 0.1 & 0.1 & Weights & 0.9 & 0.03 & 0.02 & 0.05 \\
\hline
\end{tabular}

\section{Results}

The data was divided into two parts as modeling and testing. The modeling part was used to determine best weight values of criteria (Beta coefficient "BC," rate of return "RoR," standard deviation "STD," coefficient of variation "CoV") and the testing part was used for to test these weights. The results of simulations as shown in 
Table 1.

Spearman Correlation Coefficient (SCC) was used as performance tool while measuring the fitness between the actual and predicted return orders. The Spearman correlation coefficients were given the Table 1, which presented above. These results showed the good fitness between the actual return order and predicted return order by GRA model. These results help to determine the best values of the criteria weights. According to these results most important criteria is the Beta coefficient.

When the results of the simulation are analyzed, it is evident to see that SSC test results obtained with the GRA Method positively increase when weight value given to the Beta coefficient is increased. In other words, the fairest results to the actual ones are obtained by giving weight to the Beta coefficient. For instance, when weight is given to the Beta coefficient by $100 \%$ (1.0) in the Simulation-1, the SSC between the actual results and test results increases and when weight is given to the Beta coefficient by 60\% (0.6) in the Simulation-2, the SSC decreases. These results indicate that although the independent variable, which has the strongest correlation with the return of the stocks in the following month, is the Beta coefficient among the variables used in this study, this correlation is not so much strong.

When the results are evaluated, in general, it is presented that although there is an explanatory correlation between these four variables and the return of the stocks in the following month; however this correlation is inadequate to make a stock selection.

\section{Conclusion}

Portfolio optimization operations with the risk - return perspective may produce favorable results have been presented by Harry M. Markowitz initially and other individual scientists. In this study, the efficiencies of these variables in the stock selection phase as the previous stage before optimization are analyzed. However, the results obtained indicate that these variables are not sufficient determiners in the stock selection process as much as they are in the optimization phase.

The results of the study are in parallel with the empirical studies carried by Mukherji et al. (1997) and Dhatt et al. (1999) on Korean stock market. Mukherji et al. (1997) and Dhatt et al. (1999) offer to use rates, which can be calculated with the data from the financial statements of the companies such as especially Market Value / Book Value ratios or Sales/Price ratios and Debt/Equity ratios, in stock selection instead of variables as Beta coefficient.

In this study, variables determined with return - risk perspective is used instead of financial statement ratios. However, it is presented that there is no strong relation between these variables and stocks. By the results of the study, even the Beta coefficient as the variable that has the most substantial relationship is not adequate for decision making. As such, in the following studies, empirical analysis is going to be conducted to measure the effectiveness of financial statement ratios in the stock selection with GRA method and determine whether the related literature applies to the Borsa Istanbul.

\section{References}

Albadvi, A., Chaharsooghi, S. K., \& Esfahanipour, A. (2007). Decision making in stock trading: An application of PROMETHEE. European Journal of Operational Research, 177, 673-683. http://dx.doi.org/10.1016/j.ejor.2005.11.022

Birgun, S., \& Gungor, C. (2014). A multi-criteria call center site selection by Hierarchy Grey Relational Analysis. Journal of Aeronautics and Space Technologies, 7(1), 45-52. http://dx.doi.org/10.7603/s40690-014-0004-2

Bohnenblust, H., \& Slovic, P. (1998). Integrating technical analysis and public values in risk-based decision $\begin{array}{lllll}\text { making. Reliability Engineering and System } & \text { Safety, 59, }\end{array}$ http://dx.doi.org/10.1016/S0951-8320(97)00136-1

Camelia, D., Emil, S., \& Liviu-Adrian, C. (201). Grey Relational Analysis of the financial sector in Europe. The Journal of Grey System, 25(4), 19-30.

Chen, J. H., Cheng, T. T., Ho, C. R., \& Diaz, J. F. (2014). Grey Relational Analysis and Neural Network Forecasting of REIT returns. Quantitative Finance, 14(11), 2033-2044. http://dx.doi.org/10.1080/14697688.2013.816765

Deng, J. (1989). Introduction to Grey System Theory. The Journal of Grey System, 1, 1-24.

Dhatt, M. S., Kim, Y. H., \& Mukherji, S. (1999). Relations between stock returns and fundamental variables: Evidence from a segmented market. Asia-Pacific Financial Markets, 6, 221-233. 
http://dx.doi.org/10.1023/A:1010071921399

Doğan, M. (2013). Measuring bank performance with Gray Relational Analysis: The case of Turkey. Ege Academic Review, 13(2), 215-225.

Fang-Min, L., \& Wang-Ching, C (2010). A precaution diagnosis of financial distress via Grey Situation Decision. The Journal of Grey System, 4, 395-403. http://ir.lib.tiit.edu.tw/handle/987654321/3725.

Guo, H., Xiao, X., \& Forrest, J. (2015). The forecasting of new product diffusion by Grey Model. The Journal of Grey System, 27(2), 68-77. http://dx.doi.org/10.1155/2013/625028

Hamzacebi, C., \& Pekkaya, M. (2011). Determining of stock investments with Grey Relational Analysis. Expert Systems with Applications, 38, 9186-9195. http://dx.doi.org/10.1016/j.eswa.2011.01.070

Ho, C. T. (2006). Measuring bank operations performance: An approach based on Grey Relation Analysis. The $\begin{array}{lllll}\text { Journal of the Operational Research S37-349. } & \text { Society, }\end{array}$ http://dx.doi.org/10.1057/palgrave.jors.2601985

Huang, K. Y., \& Jane, C. J. (2009). A hybrid model for stock market forecasting and portfolio selection based on ARX, Grey System, and RR theories. Expert Systems with Applications, 36, 5387-5392. http://dx.doi.org/10.1016/j.eswa.2008.06.103

Huang, W., Goto, S., \& Nakamura, M. (2004). Decision-making for stock trading based on probability by considering whole market movement. European Journal of Operational Research, 157, 227-241. http://dx.doi.org/10.1016/S0377-2217(03)00144-9

Kaygısız Ertuğ, Z., \& Girginer, N. (2013). Evaluation of banks' commercial credit applications using the Analytic Hierarchy Process and Grey Relational Analysis: A comparison between public and private banks. South African Journal of Economic and Management Sciences, 18(3), 308-324. http://dx.doi.org/10.17159/2222-3436/2015/v18n3a2

Kung, C. Y., \& Wen, K. L. (2007). Applying Grey Relational Analysis and Grey Decision-Making to evaluate the relationship between company attributes and its financial performance-A case study of venture capital enterprises in Taiwan. Decision Support Systems, 43, 842-852. http://dx.doi.org/10.1016/j.dss.2006.12.012

Kuo, Y., Yang, T., \& Huang, G. W. (2008). The use of Grey Relational Analysis in solving multiple attribute decision-making problems. Computers \& Industrial Engineering, 55, 80-93. http://dx.doi.org/10.1016/j.cie.2007.12.002

Lee, P. T. W., Lina, C. W., \& Shin, S. H. (2012). Comparative study on financial positions of shipping companies in Taiwan and Korea using Entropy and Grey Relation Analysis. Expert Systems with Applications, 39, 5649-5657. http://dx.doi.org/10.1016/j.eswa.2011.11.052

Lin, S. L., \& Wu, S. J. (2011). Is Grey Relational Analysis superior to the conventional techniques in predicting financial crisis? Expert Systems with Applications, 38, 5119-5124. http://dx.doi.org/10.1016/j.eswa.2010.09.139

Liu, J., Liu, X., Liu, Y., \& Liu, S. (2015). A new decision process algorithm for MCDM problems with interval grey numbers via Decision Target Adjustment. The Journal of Grey System, 27(2), 104-120.

Markowitz, H. M. (1952). Portfolio selection. The Journal of Finance, 7(1), 77-91. http://dx.doi.org/10.1111/j.1540-6261.1952.tb01525.x

Mukherji, S., Dhatt, M. S., \& Kim, Y. H. (1997). A Fundamental Analysis of Korean stock returns. Financial Analysts Journal, 53(3), 75-80. http://dx.doi.org/10.2469/faj.v53.n3.2086

Pan, W. T., \& Leu, P. (2016). An analysis of bank service satisfaction based on Quantile Regression and Grey Relational Analysis. Mathematical Problems in Engineering, 1-9. http://dx.doi.org/10.1155/2016/1475148

Sabau-Popa, D., Bolos, M., Scarlat, E., Delcea, C., \& Bradea, I. (2014). Effects of macroeconomic variables on stock prices of the Bucharest Stock Exchange (BSE). Academy of Economic Studies, 48(4), 103-114.

Wang, F., Li, H., \& Dong, M. (2015). Capturing the key customer requirements for complex equipment design using Grey Relational Analysis. The Journal of Grey System, 27(3), 51-70.

Wang, S. M., Hsieh, C. H., \& Sie, P. R. (2015). A grey relation analysis of the performance of listed hospitality companies in Taiwan. International Journal of Organizational Innovation, 7(3), 115-125.

Wang, Y., Shi, X. Sun, J., \& Qian, W. (2014). A grey interval relational degree-based dynamic multiattribute decision making method and its application in investment decision making. Mathematical Problems in 
Engineering, 1-6. http://dx.doi.org/10.1155/2014/607016

Wei, G. (2011). Grey Relational Analysis model for dynamic hybrid multiple attribute decision making. Knowledge-Based Systems, 55, 672-679. http://dx.doi.org/10.1016/j.knosys.2011.02.007

Yamamoto, R. (2012). Intraday Technical Analysis of individual stocks on the Tokyo Stock Exchange. Journal of Banking \& Finance, 36(11), 3033-3047. http://dx.doi.org/10.2139/ssrn.2080743

\section{Copyrights}

Copyright for this article is retained by the author(s), with first publication rights granted to the journal.

This is an open-access article distributed under the terms and conditions of the Creative Commons Attribution License (http://creativecommons.org/licenses/by/3.0/). 